Tohoku J. Exp. Med., 2004, 203, 205-210

\title{
Weekly Paclitaxel in Pretreated Metastatic Breast Cancer: Retrospective Analysis of 52 Patients
}

\author{
Esmen Baltali, Kadri Altundag, Yavuz Ozisik, Nilufer Guler and Gulten \\ TEKUZMAN \\ Hacettepe University Faculty of Medicine Department of Medical Oncology, \\ Ankara, Turkey
}

Baltali, E., Altundag, K., Ozisik, Y., Guler, N. and Tekuzman, G. Weekly Paclitaxel in Pretreated Metastatic Breast Cancer: Retrospective Analysis of 52 Patients. Tohoku J. Exp. Med., 2004, 203 (3), 205-210 — Single-agent paclitaxel has been shown to be effective as both first- and second-line treatment of metastatic breast cancer, and the efficacy and tolerability of weekly administration of paclitaxel has generated much interest. Fifty-two patients with pretreated metastatic breast cancer who were admitted to Hacettepe University between January 2001 and June 2002 were retrospectively analyzed in this study. Paclitaxel was administered weekly in a dose of $80 \mathrm{mg} / \mathrm{m}^{2}$ over 1 hour. The median number of cycles delivered was 20 weeks (range, 8 to 24). The median delivered dose was $2400 \mathrm{mg}$ (range, 960 to $3840 \mathrm{mg}$ ). At a median follow-up of 12.3 months (range, 6 to 17), all patients were assessable for response and toxicity. A complete response and partial response were observed in $7(13.5 \%)$, and $19(36.5 \%)$ patients, respectively. Overall response rate was $50 \%$. Median duration of response was 10 months (range, 3 to 16). Therapy was generally well tolerated, and toxicities were manageable. Severe leukopenia was seen in two (4\%) patients. Based on these results, we conclude that weekly paclitaxel is a well-tolerated and highly effective regimen in pre-treated metastatic breast cancer.

- metastatic breast cancer; weekly paclitaxel; chemotherapy

(C) 2004 Tohoku University Medical Press

Although fewer than $10 \%$ of patients initially diagnosed with early-stage breast cancer present with distant metastases, an estimated $20 \%$ to $30 \%$ of patients will eventually develop them (Ellis et al. 2000). The primary aim of treatment of metastatic breast cancer is palliation; treatment improves length and quality of life without hope of cure (Fossati et al. 1998), and few patients with metastatic disease are long-term survivors (Ellis et al. 2000). New treatment options are needed because many of these patients have previously received chemotherapy, either as adjuvant therapy or for metastatic disease. Tolerability of treatment for metastatic breast cancer is an important consideration.

Single-agent paclitaxel has been shown to be effective as both first- and second-line treatment of metastatic breast cancer (Perez 1998). Overall

Received January 14, 2004; revision accepted for publication May 12, 2004.

Address for reprints: Kadri Altundag, 8181 Fannin Street No: 728, Houston, Texas 77054, USA

e-mail: kaltunda@hacettepe.edu.tr 
rates of $21 \%$ to $62 \%$ have been reported in trials evaluating paclitaxel at doses of 135 to $250 \mathrm{mg} / \mathrm{m}^{2}$ administered by either 3- or 24-hour infusion as initial or subsequent therapy to women with metastatic breast cancer (Nabholtz et al. 1996; Bishop et al. 1999; Smith et al. 1999; Paridaens et al. 2000). Neutropenia is the most common toxicity in these studies.

Recently, the efficiacy and tolerability of weekly administration of paclitaxel given in a 1-hour infusion has generated much interest. Weekly paclitaxel at doses of 80 to $100 \mathrm{mg} / \mathrm{m}^{2}$ have produced an overall response rate of $2.1 \%$ to 86\% (Perez et al. 2001; Luck and Roche 2002). The rationale for this approach is that more frequent delivery of moderate doses may achieve greater efficacy than standard doses every 3 weeks (Seidman et al. 1998). Dose-dense paclitaxel may inhibit tumor regrowth between cycles and limit the emergence of malignant cell populations resistant to chemotherapy. More frequent exposure to paclitaxel may enhance its apoptotic and antiangiogenic effects (Belotti et al. 1996; Milross et al. 1996). Reduced incidence of side effects, including neutropenia and peripheral neutropenia, is another advantage of weekly administration of paclitaxel.

\section{Materials ANd Methods}

Patients with metastatic breast cancer, with measurable disease who were admitted to Hacetepe University between January 2001 and June 2002 were eligible for evaluation in this study. Patients were required to be $\geqq 18$ years of age; have an Eastern Cooperative Oncology Group performance status $\leqq 2$; have life expectancy exceeding 3 months; have bilirubin and creatinine levels less than $1.25 \times$ the upper limits of normal, and have an absolute neutrophil count above $1.5 \times 10^{9} /$ liter. Patients may have received up to two prior chemotherapy regimens for metastatic disease. Previous treatment with taxane administration on a 3-week schedule was allowed.

The criteria for exclusion included patients with known hypersensitivity; New York Heart
Association class 3 or 4 disease; pre-existing peripheral neuropathy higher than grade 1; pregnancy and/or and breast feeding; a corrected serum calcium level of $\geqq 12 \mathrm{mg} / 100 \mathrm{~mL}$ at study entry; and a second primary cancer except for basal cell carcinoma of the skin and cervical carcinoma in situ.

Pre-treatment staging procedures included a complete history and physical examination, complete blood count and liver and kidney function tests, chest X-ray, bone scan and X-ray of metastatic bones, abdominal and pelvic ultrasonography, electrocardiography and echocardiography. Computed tomography of the chest, liver, abdomen, or cranium was performed when clinically indicated.

Paclitaxel was administered weekly in a dose of $80 \mathrm{mg} / \mathrm{m}^{2}$ over 1 hour. Pre-medications consisted of intravenous diphenhydramine $50 \mathrm{mg}$ and $\mathrm{H}_{2}$ blocker (such as intravenous ranitidine 50 $\mathrm{mg}$ ), and intravenous dexamethasone $16 \mathrm{mg}$ all administered 30 to 60 minutes before treatment. If no hypersensitivity reactions were seen after first paclitaxel administration, the dose of dexamethasone was reduced by half each consecutive week. Treatment continued until the disease progressed or severe toxicity occurred. Physical examination, complete blood count and toxicity assessment were performed weekly. Serum chemistry was assessed every 2 weeks. Dose modifications were evaluated according to guidelines of the European Organization for Research and Treatment of Breast Cancer Cooperative Group (1998). Adverse effects were determined according to World Health Organization (1999) criteria. Mild toxicity indicates grade 1, and grades increase up to grade 4 as the severity of toxicity increases.

Tumor measurements were obtained every eight cycles to evaluate response. All responses were confirmed by a second measurement after an additional 4 weeks. Response criteria were as follows: (a) complete response, a disappearance of the primary tumor clinically and radiologically; (b) partial response, a tumor reduction of $\geqq 50 \%$; 
(c) stable disease, a tumor reduction of $<50 \%$, or an increase in tumor size of $<25 \%$; and (d) progressive disease, an increase in tumor size of $\geqq 25 \%$ or appearance of any new lesion. Statistical analysis was evaluated by the $\chi^{2}$ test. Duration of response was calculated from the day the response was first recorded until the day of disease progression.

\section{Results}

Fifty-two patients were retrospectively analyzed. Patient characteristics are listed in Table 1. The median age of the patients was 49 (range, 28 to 70 ). A majority of patients (90\%) had an Eastern Cooperative Oncology Performance status of 0 or 1 . The majority of patients $(89 \%)$ had received adjuvant or neoadjuvant treatment. All patients who had positive hormone receptor status had received tamoxifen in the adjuvant or neoadjuvant setting. A total of $20(38 \%)$ patients had received prior taxane therapy in the metastatic setting ( 8 patients with paclitaxel, 12 patients with docetaxel). All patients had received anthracycline containing regimens in the metastatic or adjuvant or neoadjuvant setting (Table 1).

The median number of cycles delivered was 20 weeks (range, 8 to 24 ). The median delivered dose was $2400 \mathrm{mg}$ (range, 960 to $3840 \mathrm{mg}$ ).

At a median follow-up of 12.3 months (range 6 to 17), all patients were assessable for response and toxicity. Complete response or partial response was observed in seven $(13.5 \%)$, and $19(36.5 \%)$ patients, respectively. The overall response rate was $50 \%$. There were $5(10 \%)$ patients categorized as stable diseases, and 21 (40\%) categorized as progressive diseases. the clinical benefit was $60 \%$ (Table 2). These overall response rates were not statistically different between patients who had received prior therapy with taxane and those who had not $(55 \%$ vs. $45 \%$ ). Response rates were different between patients with visceral metastases and those with soft-tissue metastases. Progressive disease was more commonly seen in patients with visceral metastases than in patients with soft-tissue me-
TABle 1. Patient characteristics

\begin{tabular}{|c|c|c|}
\hline & No. & $\%$ \\
\hline Total no. of patients & 52 & 100 \\
\hline Median age & 49 & \\
\hline Range & $28-70$ & \\
\hline \multicolumn{3}{|l|}{ Menopausal status } \\
\hline Premenopausal & 20 & 38 \\
\hline Postmenopausal & 32 & 62 \\
\hline \multicolumn{3}{|l|}{ ER status } \\
\hline Negative & 16 & 31 \\
\hline Positive & 28 & 54 \\
\hline Unknown & 8 & 15 \\
\hline \multicolumn{3}{|c|}{ Performance status (ECOG) } \\
\hline 0 & 32 & 62 \\
\hline 1 & 15 & 28 \\
\hline 2 & 5 & 10 \\
\hline \multicolumn{3}{|l|}{ Site of metastasis } \\
\hline Soft tissue & 20 & 38 \\
\hline Bone & 16 & 31 \\
\hline Liver & 8 & 15 \\
\hline Lung & 4 & 8 \\
\hline Other & 4 & 8 \\
\hline \multicolumn{3}{|l|}{ Prior chemotherapy } \\
\hline Adjuvant therapy & 32 & 62 \\
\hline Neoadjuvant therapy & 14 & 27 \\
\hline Metastatic therapy & 52 & 100 \\
\hline \multicolumn{3}{|l|}{ Prior therapy } \\
\hline Taxane & 20 & 38 \\
\hline Anthracycline & 52 & 100 \\
\hline
\end{tabular}

ER status, estrogen receptor status; ECOG, Eastern Cooperative Oncology Group.

TABLE 2. Response to therapy

\begin{tabular}{lcl}
\hline Response & No. of patients & $\%$ \\
\hline CR & 7 & 13.5 \\
PR & 19 & 36.5 \\
SD & 5 & 10 \\
PD & 21 & 40 \\
Total & 52 & 100 \\
\hline
\end{tabular}

CR, complete response; PR, partial response; $\mathrm{SD}$, stable disease; $\mathrm{PD}$, progressive disease. 
tastases (52\% vs. 24\%) (Table 3). Median duration of response was 10 months (range 3 to 16). Median duration of response for metastases that were either visceral or soft tissue only was 8.5 months and 16 months, respectively.

Therapy was generally well tolerated, and effects of toxicities were manageable. Grade 3 or 4 leukopenia was seen in two (4\%) patients. No neutropenia-associated fever occurred in these patients, who had received two different chemotherapy regimens for metastatic disease. Of 52 patients, $2(3.5 \%)$ and $5(10 \%)$ developed grade 1 and 2 peripheral neuropathy. Gastrointestinal toxicities (stomatitis, nausea-vomiting, diarrhea) were rarely seen. and grades 1 and 2 were easily manageable (Table 4).
TABLE 3. Response to therapy according to metastatic sites

\begin{tabular}{lccc}
\hline \multirow{3}{*}{ Response } & \multicolumn{3}{c}{ No. $(\%)$} \\
\cline { 2 - 4 } & Soft tissue & Visceral & Total \\
\hline CR & $5(24)$ & $2(6)$ & $7(13.5)$ \\
PR & $9(43)$ & $10(32)$ & $19(36.5)$ \\
SD & $2(9)$ & $3(10)$ & $5(10)$ \\
PD & $5(24)$ & $16(52)$ & $21(40)$ \\
Total & $21(100)$ & $31(100)$ & $52(100)$ \\
\hline
\end{tabular}

$\mathrm{CR}$, complete response; PR, partial response; $\mathrm{SD}$, stable disease; $\mathrm{PD}$, progressive disease.

TABLE 4. Treatment-related toxicity

\begin{tabular}{|c|c|c|c|c|c|c|c|c|}
\hline & \multicolumn{2}{|c|}{ Grade 1} & \multicolumn{2}{|c|}{ Grade 2} & \multicolumn{2}{|c|}{ Grade 3} & \multicolumn{2}{|c|}{ Grade 4} \\
\hline & No. & $\%$ & No. & $\%$ & No. & $\%$ & No. & $\%$ \\
\hline Nausea-vomiting & 14 & 27 & 4 & 7.5 & 0 & 0 & 0 & 0 \\
\hline Stomatitis & 3 & 6.5 & 1 & & 0 & 0 & 0 & 0 \\
\hline Diarrhea & 3 & 6.5 & 2 & 3.5 & 0 & 0 & 0 & 0 \\
\hline Hepatotoxicity & 3 & 6.5 & 1 & 2 & 0 & 0 & 0 & 0 \\
\hline Anemia & 3 & 6.5 & 0 & 0 & 0 & 0 & 0 & 0 \\
\hline Leukopenia & 9 & 17 & 3 & 6.5 & 1 & 2 & 1 & 2 \\
\hline Neuropathy & 5 & 10 & 2 & 3.5 & 0 & 0 & 0 & 0 \\
\hline Alopecia & 6 & 13 & 10 & 19.5 & 5 & 10 & 0 & 0 \\
\hline Nail disorder & 7 & 14 & 1 & 2 & 0 & 0 & 0 & 0 \\
\hline Arthralgia/myalgia & 9 & 17 & 4 & 7.5 & 2 & 3.5 & 0 & 0 \\
\hline
\end{tabular}

$\mathrm{CR}$, complete response; $\mathrm{PR}$, partial response; $\mathrm{SD}$, stable disease; $\mathrm{PD}$, progressive disease.

\section{Discussion}

Metastatic breast cancer is still considered an incurable disease, and the primary aim of treatment is palliation. The best that can be expected of treatment is that it will improve length and quality of life, and there is no hope of cure (Fossati et al. 1998). Tolerability of treatment is an important consideration and the efficacy and tolerability of weekly administration of paclitaxel given in 1-hour infusion has generated much interest.
Weekly paclitaxel at doses of 80 to $100 \mathrm{mg} / \mathrm{m}^{2}$ has produced an overall response rate of $2.1 \%$ to 86\% (Perez et al. 2001; Luck and Roche 2002).

We observed that weekly paclitaxel therapy was well tolerated and showed some efficacy in patients who had received one or two chemotherapy regimens for metastatic disease.

We found an overall response rate of $50 \%$ with weekly paclitaxel $\left(80 \mathrm{mg} / \mathrm{m}^{2}\right)$ in pre-treated metastatic breast cancer patients. The clinical benefit was $60 \%$. Our results were comparable 
with response rates observed in other phase II weekly paclitaxel studies, although the eligibility criteria of these studies were different (Perez et al. 2001; Gori et al. 2002; Luck and Roche 2002).

As increasingly more patients are receiving anthracyclines in the adjuvant setting, the use of taxanes as front-line chemotherapy will increase. In the first reported study of weekly paclitaxel administered as first-line chemotherapy for metastatic breast cancer, paclitaxel $100 \mathrm{mg} / \mathrm{m}^{2}$ resulted in a $40 \%$ overall response rate and $67 \%$ clinical benefit. Time to progression was 189 days, the duration of response was 180 days, and overall survival was 544 days (Wist et al. 2004). Thus, this study has shown that weekly paclitaxel as first-line therapy for metastatic or advanced breast cancer produces comparable response rates and less toxicity than when the drug is given every 3 weeks. More studies are warranted to demonstrate its role as front-line treatment.

Another study evaluated the activity and toxicity of weekly paclitaxel, $80 \mathrm{mg} / \mathrm{m}^{2}$ as firstline chemotherapy in elderly patients ( $>70$ years of age) with hormone-refractory metastatic breast cancer. Of 23 patients who were evaluable for response, 10 had partial responses (38\%), and 9 had stable disease $(35 \%)$, while 4 had disease progression $(15 \%)$. The median duration of response was 194 days ( $>6$ months). Overall, treatment was relatively well tolerated (Ten Tije et al. 2004). This study also showed that weekly paclitaxel at this dose and schedule is an effective treatment regimen in the elderly patient with metastatic breast cancer, and that this treatment is feasible. Thus, weekly regimens may be more suitable for elderly patients and those with a lower performance status.

The toxicity profile of weekly paclitaxel was also favorable. Only two patients (4\%) developed grade 3 or 4 leukopenia without any fever. No grade 3 or 4 neuropathy was observed to cause reduction of the dose or cancellation of the treatment. Gastrointestinal toxicities were usually grade 1 or 2 and manageable.

Minimal toxicity and satisfactory efficacy may provide an opportunity to combine this regimen with other agents including trastuzumab. A Phase IIb randomized study showed the superiority of a weekly paclitaxel and trastuzumab combination over single agent weekly paclitaxel (Gasparini et al. 2003). Direct comparison of weekly paclitaxel with 3-weekly paclitaxel may enlighten us as to the efficacy and toxicity profiles of these regimens.

In conclusion, weekly paclitaxel is well tolerated and a highly effective regimen in pretreated metastatic breast cancer.

\section{References}

Belotti, D., Vergani, V., Drudis, T., Borsotti, P., Pitelli, M.R., Viale, G., Giarazzi, R. \& Taraboletti, G. (1996) The microtubule-affecting drug paclitaxel has antiangiogenic activity. Clin. Cancer Res., 2, 1843-1849.

Bishop, J.F., Dewar, J., Toner, G.C., Smith, J., Tattersall, M.H., Olver, I.N., Ackland, S., Kennedy, I., Goldstein, D., Gurney, H., Walpole, E., Levi, J., Stephenson, J. \& Canetta, R. (1999) Initial paclitaxel improves outcome compared with CMVP combination therapy as front-line therapy in untreated metastatic breast cancer. J. Clin. Oncol., 17, 2355-2364.

Ellis, M.J., Hayes, D.F. \& Lippman, M.E. (2000) Treatment of metastatic breast cancer, In: Diseases of the Breast, edited by J.R. Harris, M.E. Lippman \& M. Morrow, Philadelphia, PA, Lippincott Williams \& Wilkins, pp. 749-748.

Fossati, R., Confalonieri, C., Torrie, V., Ghislandi, E., Penna, A., Pistotti, V., Tinazzi, A. \& Liberati, A. (1998) Cytotoxic and hormonal treatment for metastatic breast cancer: a systematic review of published randomized trials involving 31,510 women. J. Clin. Oncol., 16, 3439-3460.

Gori, S., Mosconi, A.M., Basurtol, C., Cherubinil, R., De Angelis, V., Tonato, M. \& Colozza, M. (2002) Weekly paclitaxel in metastatic breast cancer patients: a phase II study. Tumori, 88 , 470-473.

Gasparini, G., Gion, M., Crivellari, D., Morabito, A., Rocco, S., Spada, A., Cognetti, F., Flippelli, G., Silingardi, V. \& Amadori, D. (2003) Interim analysis of a randomized phase IIb study of weekly paclitaxel (PCT) with or without trastuzumab (T) as first-line therapy of patients with HER-2/neu positive metastatic breast cancer 
(MBC): Clinical and biologic results. Proc. Am. Soc. Clin. Oncol., 22, 35, (abstr 138).

Luck, H.J. Roche, H. (2002) Weekly paclitaxel: an effective and well-tolerated treatment in patients with advanced breast cancer. Crit. Rev. Oncol. Hematol., 44 (Suppl.), 15-30.

Manual for Clinical Research in Breast Cancer: EORTC Breast Cancer Cooperative Group (1998) Almere, the Netherlands, Excerpta Medica, 96-97.

Milross, C.G., Mason, K.A., Hunter, N.R., Chunk, W.K., Peters, L.J. \& Milas, L. (1996) Relationship of mitotic arrest and apoptosis to tumor effect of paclitaxel. J. Natl. Cancer Inst., 88, 1308-1314.

Nabholtz, J.M., Gelmon, K., Bontenbal, M., Spielmann, M., Catimel, G., Conte, P., Klaassen, U., Namer, M., Bonneterre, J., Fumoleau, P. \& Winograd, B. (1996) Multicenter, randomized comparative study of two doses of paclitaxel in patients with metastatic breast cancer. J. Clin. Oncol., 14, 1858-1867.

Paridaens, R., Biganzoli, L., Bruning, P., Klijn, J.G., Gamucci, T., Houston, S., Coleman, R., Schacter, J., Van Vreckem, A., Sylvester, R., Awada, A., Wildiers, J. \& Piccart, M. (2000) Paclitaxel versus doxorubicin as first-line single-agent chemotherapy for metastatic breast cancer: A European Organization for Research and Treatment of Cancer randomized study with cross-over. J. Clin. Oncol., 18, 724-733.

Perez, E.A. (1998) Paclitaxel in breast cancer. Oncologist, 3, 375-389.

Perez, E.A., Vogel, A.C., Irwin, D.H., Kirshner, J.J. \& Patel, R. (2001) Multicenter phase II trial of weekly paclitaxel in women with metastatic breast cancer. J. Clin. Oncol., 19, 4216-4223.

Seidman, A.D., Hudis, C.A., Albanel, J., Tong, W., Tepler, I., Currie, V., Moynahan, M.E., Theodolou, M., Gollub, M., Baselga, J. \& Norton, L. (1998) Dose-dense therapy with weekly 1-hour paclitaxel infusion in the treatment of metastatic breast cancer. J. Clin. Oncol., 16, 3353-3361.

Smith, R.E., Brown, A.M., Mamounas, E.P., Anderson S.J., Lembersky, B.C., Atkins, J.H., Shibata, H.R., Baez, L., DeFusco, P.A., Davila, E., Tipping, S.J., Bearden, J.D. \& Thirlwell, M.P. (1999) Randomized trial of 3-hour versus 24-hour infusion of high-dose paclitaxel in patients with metastatic or locally advanced breast cancer. National Surgical Adjuvant Breast and Bowel Project protocol B-26. J. Clin. Oncol., 17, 3403-3411.

Ten Tije, A.J., Smorenburg, C.H., Seynaeve, C., Sparreboom, A., Schothorst, K.L., Kerkhofs, L.G., van Reisen, L.G., Stoter, G., Bontenbal, M. \& Verweij, J. (2004) Weekly paclitaxel as first-line chemotherapy for elderly patients with metastatic breast cancer. A multicenter phase II trial. Eur. J. Cancer, 40, 352-357.

WHO Hand Book for Reporting Results of Cancer Treatment (1999) Geneva, World Health Organization (WHO offset Publication) No. 48, pp.16-27.

Wist, E.A., Sommer, H.H., Ostenstad, B., Risberg, T. \& Fjaestad, K. (2004) Weekly one-hour paclitaxel as first-line chemotherapy for metastatic breast cancer. Acta Oncol., 43, 11-14. 